\title{
Microalbuminuria in pediatric patients with hypertension
}

\author{
Nataša Marčun Varda \\ Department of Paediatrics, University Medical Centre Maribor, Maribor, Slovenia; natasa.marcunvarda@amis.net
}

Received 5 March 2013; revised 2 April 2013; accepted 13 April 2013

Copyright (C) 2013 Nataša Marčun Varda. This is an open access article distributed under the Creative Commons Attribution License, which permits unrestricted use, distribution, and reproduction in any medium, provided the original work is properly cited.

\begin{abstract}
Microalbuminuria in adults has been found to be an early indicator of both renal and systemic vascular disease, as well as significant cardiovascular risk predictor and therapeutic marker. Its role in essential hypertension in adults has also been well established. As diseases like hypertension and obesity have their roots in childhood and are already present in children, influencing the morbidity in adulthood, the role of microalbuminuria has been extensively investigated in children as well. Most investigations have been performed in diabetic children, confirming its clinical significance. There is also enough evidence to suggest that microalbuminuria in obese children should be taken as seriously as in children with diabetes. In children with hypertension rare studies also indicate that its presence identifies hypertensive children with higher risk, although the exact role has to be confirmed in prospective and larger studies. The mechanisms of microalbuminuria onset could be the result of renal damage secondary to hypertension or underlying renal and systemic endothelial dysfunction. Evidence from small intervention studies in children with microalbuminuria also suggests that early intervention with antihypertensive drugs is likely to be beneficial, pointing out the role of microalbuminuria as a therapeutic marker in children too. In addition, we have to stress the importance of follow-up of children with microalbuminuria, confirmation of its persistence and identification of progression. However, longitudinal prospective studies in children, investigating its future cardiovascular risk, are still lacking.
\end{abstract}

Keywords: Microalbuminuria; Hypertension; Cardiovascular Diseases; Child

\section{INTRODUCTION}

Hypertension is one of the most important cardiovascular risk factors in both children and adults [1,2]. It is clearly identifiable in childhood, with increasing prevalence due to increased prevalence of childhood obesity [3-5], and associated with hypertension and cardiovascular diseases in adulthood $[2,6]$. Unfortunately, there is no prospective study, demonstrating direct association of hypertension in childhood with cardiovascular events later in adult life [7]. In recent years early markers of additional cardiovascular risk of these patients have been searched and investigated; among them also found microalbuminuria [8-11].

Microalbuminuria is defined as increased excretion of small quantities of albumin in urine, that is undetectable by standard protein dipstick testing, ranging from 30 to $300 \mathrm{mg}$ per day [12], and is usually diagnosed on the basis of three positive tests over a 3 - 6-month period [13]. It can also be detected in a random spot urine as albumin creatinine ratio $[14,15]$. Microalbuminuria arises from increased leakage of albumin through the complex glomerular filtration barrier, requiring changes in physiochemical properties of its components that are the consequence of renal damage [16]. It may also reflect impaired vascular function in general [17]. There is also a possibility that level of albumin excretion in individuals represent the vascular state at birth, influenced with both genetic and environmental factors, that is associated with increased or reduced susceptibility to organ damage [17]. Complete understanding of mechanisms through which microalbuminuria occurs will enable development of potential therapies, influencing its onset and regression [16, 17].

It has been shown in adults that microalbuminuria is an early sign of both renal and systemic vascular disease $[18,19]$. In addition, it is a cardiovascular risk predictor, with effect independent from other risk factors [20]. It is also a sensitive marker for detecting new onset of other 
cardiovascular risk factors, such as hypertension and diabetes [21,22]. Moreover, intervention studies have been performed, investigating the effect of microalbuminuria lowering in "healthy" individuals with microalbuminuria, showing therapeutic cardioprotection [23]. The role of microalbuminuria in adult patients with essential hypertension has also been confirmed, its routine measurement in hypertensive patients recommended and in the case of microalbuminuria intensified antihypertensive treatment introduced [24].

We are of the opinion that findings in adults cannot be simply extrapolated to children; therefore there is a need for relevant longitudinal studies to be performed in children and adolescents. Unfortunately, there are no studies yet, investigating the role of microalbuminuria in children as cardiovascular risk factor later in adult life, which is important future task. Anyway, the clinical significance of microalbuminuria in diabetic children has been confirmed $[25,26]$ as well as in some other diseases in children [27-30]. Some small intervention studies have also been conducted, suggesting that early intervention with medications is likely to be beneficial in children too $[31,32]$.

\section{MICROALBUMINURIA IN HEALTHY CHILDREN}

The prevalence of microalbuminuria in general population was found to be $7.8 \%, 6.1 \%$ in males, and $9.7 \%$ in females [33]. It was almost twofold prevalent among 6 19-year-old than in 20 - 39-year-old, increasing continuously starting at 40-year-old [33]. Possible explanation for high prevalence in adolescents might be the influence of orthostatic proteinuria [34]. A positive association was found between albumin excretion rate and pubertal developmental stage [35]. In addition, the problem of methodology [14,17], age, height dependency [36] and possible transient elevations [37] have to be mentioned. In a study investigating 3856 children the prevalence of microalbuminuria and macroalbuminuria was $6.5 \%$ and $0.6 \%$, respectively, and regression established in $75.4 \%$ [37]. Recently, normative data on albumin excretion in healthy adolescents have been published [38]. It has been found that in healthy children, albuminuria relates to fasting insulin, but not to blood pressure, body mass index, lipid levels, fasting glucose, or insulin resistance $[38,39]$.

It has been pointed out that children make ideal subjects to study the natural history of microalbuminuria given their relative lack of multiple morbidities commonly seen in adults [38]. It is very important in the context of results of studies in general population, showing that only slightly raised levels of albumin relates to increased cardiovascular risk [40]. It was also confirmed in recent meta-analysis [41]. Studies, investigating natural course of established microalbuminuria in healthy children are one of the important future task.

\section{MICROALBUMINURIA IN DIFFERENT CHILDHOOD DISEASES}

Microalbuminuria was most extensively investigated in children with both type 1 and type 2 diabetes $[25,26]$ and its significant role established. In recent years its assessment has been utilized as a screening test for the presence of diabetes-related kidney disease [38]. In one of the studies it was present in $11.2 \%$ of type 1 diabetic children and proteinuria in another $6.8 \%$ of them [42]. In other studies even higher percentages of both have been found [43]. Significant association between the occurrence of microalbuminuria or proteinuria and poor glucose control has been confirmed $[26,43]$. In addition to poor glycemic control, clinical markers of insulin resistance were associated with its development [44]. There might be also the influence of some genetic polymorphisms [39]. It has also been found out that children and adolescents with type 1 diabetes with borderline microalbuminuria are more than twice as likely to develop persistent microalbuminuria compared to normoalbuminuria [44]. Natural course of microalbuminuria has also been studied [45]. The prevalence of microalbuminuria and macroalbuminuria in type 2 diabetic children was $18.5 \%$ and $2.9 \%$, respectively [37]. This study also found out that microalbuminuria in these patients strongly predicts progression to macroalbuminuria, which supports its annual screening [37]. In another study significantly higher prevalence of microalbuminuria in diabetic children compared to adults was detected, corrected for glycemic control and duration of diabetes [46]. In diabetic patients role of hypertension in diabetes complications such as microalbuminuria were also investigated $[47,48]$. In one study, maternal blood pressure predicted microalbuminuria in children with diabetes [49]. Some small intervention studies have also been performed and found out that long-lasting treatment with angiotensin-converting enzyme inhibitors seems to be able to induce persistent remission, especially when associated with good metabolic control and high HDL-cholesterol levels $[31,50,51]$. Ongoing study investigating the role of angiotensin-converting enzyme inhibitors, statins, or combination therapy in type 1 diabetic children will provide important data on the potential renal and cardiovascular protective effects of these drugs [32].

In obese children, microalbuminuria relates to multiple measures of insulin resistance [39]. It predicts glucose intolerance and metabolic syndrome [52] and is associated with cardiovascular risk factors, including hypertension [27]. Its prevalence has been found to be $18 \%$ [28]. 
Obesity is associated with glomerular hyperperfusion and hyperfiltration, leading to obesity-related glomerulopathy [53]. In addition, authors suggested that recurrent states of postprandial glycemia increase oxidative stress on the vasculature, leading to endothelial dysfunction and microalbuminuria [54]. Whether microalbuminuria predicts cardiovascular diseases in children as it does in adults, remains to be investigated [52]. However, it seems to be a strong predictor of insulin resistance and hypertension, both of which are strong risk factors for future cardiovascular disease and death [55]. Again, there are no long-term follow-up studies into late adulthood to provide direct cardiovascular morbidity and mortality.

Microalbuminuria has also been investigated in numerous nephrologic and other diseases, such as microhaematuria [56], sickle cell anemia [30,57], low-birth weight [58], congenital solitary kidneys [59], orthostatic proteinuria [34], metabolic syndrome [28].

At present, the data suggests that impairment of glucose metabolism, obesity-related proatherosclerotic pathways and the impact of haemodynamic load represent major factors for microalbuminuria development in children [35]. If persistent microalbuminuria is present, further investigation of cardiovascular factors, careful follow-up and intensive lifestyle interventions should be performed [35]. Some authors also proposed screening of children for proteinuria or microalbuminuria, mainly in high-risk groups, as reversibility of organ damage in early stages is possible [53]. However, other authors did not recommend it for general population, but only for high-risk patients, namely overweight and diabetic adolescents [27].

\section{MICROALBUMINURIA IN CHILDREN WITH HYPERTENSION}

The role of microalbuminuria in adults with hypertension is well established, representing a marker of cardiovascular complications and impaired renal function [24, $60,61]$. In children, however, long-term studies are not available, but there are some studies, investigating microalbuminuria in the context of early sign of hypertensive organ damage $[8,62]$. Possible mechanisms of microalbuminuria onset could be the result of renal damage secondary to hypertension or underlying general, renal and systemic, endothelial dysfunction [24].

The prevalence of microalbuminuria in adult patients with hypertension in large population studies is quite different, varying from $8 \%$ to $23 \%[63,64]$. In children, only few studies have been performed and demonstrated, that the prevalence is around $20 \%$ [9]. In some other studies even higher prevalence was found out [65]. In one of the studies investigating patients with white coat hypertension, microalbuminuria was not detected, sug- gesting its low hypertension-related renal risk [20]. The mean value of microalbuminuria in these patients was significantly lower than in patients with essential hypertension [20]. In another study investigating hypertensive target organ damage mean value of microalbuminuria was found to be $29.3 \pm 11.4 \mathrm{mg}$ per day [11]. Microalbuminuria was also strongly associated with left ventricular hypertrophy [8]. Some authors demonstrated positive association between family history of hypertension and microalbuminuria, indicating its increased predisposition to it [65]. It has also been shown that hypertension in childhood is associated with microalbuminuria in adulthood in African Americans but not in whites, suggesting that African Americans may be more susceptible to blood pressure-related renal damage than whites [10].

One intervention study with hydroclorothiazide and angiotensin-converting enzyme inhibitor treatment specifically examined the effects of microalbuminuria lowering on regression of left ventricular hypertrophy in paediatric patients with hypertension and found out that microalbuminuria is its strong predictor, explaining $78 \%$ of the left ventricular hypertrophy [66].

Despite numerous studies in adults and studies in paediatric patients microalbuminuria has not been formally recommended as diagnostic marker in hypertensive children [67]. However, in recently published recommendations of the European Society of Hypertension about management of hypertensive children measurement of microalbuminuria has been mentioned as one of the routine tests performed in all hypertensive children, with the remark that its assessment has yet to be fully established [68]. At our department microalbuminuria screening has been performed in previous years and recommended as one of the basic tests of hypertensive organ damage [69]. We are of opinion, like most of the authors that ascertainment of the exact role of microalbuminuria in children with hypertension needs further studies, investigating also microalbuminuria predictors and possible resolution after treatment strategies [39]. Furthermore, longterm prospective studies with follow-up into adulthood are needed to find out its potential direct cardiovascular and renal risk.

\section{CONCLUSION}

In recent years the role of microalbuminuria in healthy children and in different childhood diseases, including essential hypertension, has been thoroughly investigated. Most investigations have been performed in diabetic children, confirming its clinical significance. The role of microalbuminuria in other high-risk paediatric populations such as hypertensive children has also been suggested, necessitating further confirmation. We also need studies 
investigating microalbuminuria predictors and possible effect of treatment strategies on its resolution. Moreover, prospective studies of healthy children with microalbuminuria are needed to investigate possible role of microalbuminuria in cardiovascular risk in general population. In addition, long-term prospective studies of children with hypertension and other high-risk paediatric populations with follow-up into adulthood are needed to find out its possible direct impact on cardiovascular morbidity and mortality. Finally, significance of microalbuminuria to be used as a target for early treatment and even prevention in children has to be established.

\section{REFERENCES}

[1] Vasan, R.S., Larson, M.G., Leip, E.P., Evans, J.C., O'Donnell, J.C., Kannel, W.B. and Levy, D. (2001) Impact of high-normal blood pressure on the risk of cardiovascular disease. The New England Journal of Medicine, 345, 1291-1297. doi:10.1056/NEJMoa003417

[2] Berenson, G.S. (2002) Childhood risk factors predict adult risk associated with subclinical cardiovascular disease: The Bogalusa heart study. American Journal of Cardiology, 90, 3L-7L. doi:10.1016/S0002-9149(02)02953-3

[3] McNiece, K.L., Poffenbarger, T.S., Turner, J.L., Franco, K.D., Sorof, J.M. and Portman, R.J. (2007) Prevalence of hypertension and pre-hypertension among adolescents. Journal of Pediatrics, 150, 640-644. doi:10.1016/i.jpeds.2007.01.052

[4] Assadi, F. (2012) The growing epidemic of hypertension among children and adolescents: A challenging road ahead. Pediatric Cardiology, 33, 1013-1020. doi:10.1007/s00246-012-0333-5

[5] Sorof, J. and Daniels, S. (2002) Obesity hypertension in children: A problem of epidemic proportions. Hypertension, 40, 441-447. doi:10.1161/01.HYP.0000032940.33466.12

[6] Lauer, R.M., Clarke, W.R., Mahoney, L.T. and Witt, J. (1993) Childhood predictors for high adult blood pressure. The Muscatine Study. Pediatric Clinics of North America, 40, 23-40.

[7] Lawes, C.M., Vander Hoorn, S., Law, M.R., Elliott, P., MacMahon, S. and Rodgers, A. (2006) Blood pressure and the global burden of disease 2000. Part II: Estimates of attributable burden. Journal of Hypertension, 24, 423430. doi:10.1097/01.hjh.0000209973.67746.f0

[8] Assadi, F. (2008) Relation of left ventricular hypertrophy to microalbuminuria and C-reactive protein in children and adolescents with essential hypertension. Pediatric Cardiology, 29, 580-584. doi:10.1007/s00246-007-9153-4

[9] Seeman, T., Pohl, M., Palyzova, D. and John, U. (2012) Microalbuminuria in children with primary and whitecoat hypertension. Pediatric Nephrology, 27, 461-467. doi:10.1007/s00467-011-2019-2

[10] Hoq, S., Chen, W., Srinivasan, S.R. and Berenson, G.S. (2002) Childhood blood pressure predicts adult micro- albuminuria in African Americans, but not in whites: The Bogalusa heart study. American Journal of Hypertension, 15, 1036-1041. doi:10.1016/S0895-7061(02)03066-2

[11] Antoniewicz, J., Litwin, M., Daszkoska, J., Nemirska, A., Sladowska, J., Wierzbicka, A., Wawer, Z. and Grenda, R. (2006) Target organ damage in children with newly diagnosed and untreated essential hypertension. Przegl Lek, 63, 101-106.

[12] Rowe, D.J., Dawnay, A. and Watts, G.F. (1990) Microalbuminuria in diabetic subjects. Annals of Clinical Biochemistry, 27, 297-312.

[13] Donnelly, R. and Rea, R. (2003) Microalbuminuria: How informative and reliable are individual measurements? Journal of Hypertension, 21, 1229-1233. doi:10.1097/00004872-200307000-00003

[14] Chae, H.W., Shin, J.I., Kwon, A.R., Kim, H.S. and Kim, D.H. (2012) Spot urine albumin to creatinine ratio and serum cystatin $\mathrm{C}$ are effective for detection of diabetic nephropathy in childhood diabetic patients. Journal of Korean Medical Science, 27, 784-787. doi:10.3346/jkms.2012.27.7.784

[15] Assadi, F.K. (2002) Quantitation of microalbuminuria using random urine samples. Pediatric Nephrology, 17, 107-110. doi:10.1007/s00467-001-0762-5

[16] Singh, A. and Satchell, S.C. (2011) Microalbuminuria: Causes and implications. Pediatric Nephrology, 26, 19571965. doi:10.1007/s00467-011-1777-1

[17] De Zeeuw, D., Parving, H.H. and Henning, R.H. (2006) Microalbuminuria as an early marker for cardiovascular disease. Journal of the American Society of Nephrology, 17, 2100-2105. doi:10.1681/ASN.2006050517

[18] Viberti, G.C., Hill, R.D., Jarret, R.J., Argyropoulos, A., Mahmud, U. and Keen, H. (1982) Microalbuminuria as a predictor of clinical nephropathy in insulin-dependent diabetes mellitus. Lancet, 1, 1430-1432. doi:10.1016/S0140-6736(82)92450-3

[19] Weir, M.R. (2004) Microalbuminuria in type 2 diabetes: An important, overlooked cardiovascular risk factor. The Journal of Clinical Hypertension, 6, 134-143. doi:10.1111/j.1524-6175.2004.02524.X

[20] Gerstein, H.C., Mann, J.F., Yi, Q., Zinman, B., Dinneen, S.F., Hoogwerf, B., Hallé, J.P., Young, J., Rashkow, A., Joyce, C., Nawaz, S., Yusuf, S. and HOPE Study Investigators (2001) Albuminuria and risk of cardiovascular events, death, and heart failure in diabetic and nondiabetic individuals. JAMA, 286, 421-426. doi:10.1001/jama.286.4.421

[21] Brantsma, A.H., Bakker, S.J., de Zeeuw, D., de Jong, P.E. and Gansevoort, R.T. (2006) Urinary albumin excretion as a predictor of the development of hypertension in the general population. Journal of the American Society of Nephrology, 17, 331-335.

[22] Brantsma, A.H., Bakker, S.J., Hillege, H.L., de Zeeuw, D., de Jong, P.E., Gansevoort, R.T. and PREVEND Study Group (2005) Urinary albumin excretion and its relation with C-reactive protein and metabolic syndrome in the prediction of type 2 diabetes. Diabetes Care, 28, 25252530. doi:10.2337/diacare.28.10.2525

[23] Asselbergs, F.W., Diercks, G.F.H., Hillenge, H., van 
Boven, A.J., Janssen, W.M., Voors, A.A., de Zeeuw, D., de Jong, P.E., van Veldhuisen, D.J. and van Gilst, W.H. and Prevention of Renal and Vascular Endstage Disease Intervention Trial (PREVEND IT) Investigators (2004) Prevention of renal and vascular endstage disease intervention trial (PREVEND IT) investigators. Effects of fosinopril and pravastatin on cardiovascular events in subjects with microalbuminuria. Circulation, 110, 28092816. doi:10.1161/01.CIR.0000146378.65439.7A

[24] Crippa, G. (2002) Microalbuminuria in essential hypertension. Journal of Human Hypertension, 16, S74-S77. doi:10.1038/si.jhh.1001348

[25] Sellers, E.A.C., Blydt-Hansen, T.D., Dean, H.J., Gibson, I.W., Birk, P.E. and Ogborn, M. (2009) Microalbuminuria and renal pathology in first nation youth with type 2 diabetes. Diabetes Care, 32, 786-790. doi: $10.2337 / \mathrm{dc} 08-1828$

[26] Alleyn, C.R., Volkening, L.K., Wolfson, J., RodriguezVentura, A., Wood, J.R. and Laffel, L.M.B. (2010) Occurrence of microalbuminuria in young people with type 1 diabetes: Importance of age and diabtes duration. Diabetic Medicine, 27, 532-537. doi:10.1111/j.1464-5491.2010.02983.x

[27] Nguyen, S., McCulloch, C., Brakeman, P., Portale, A. and Hsu, C. (2008) Being overweight modifies the association between cardiovascular risk factors and microalbuminuria in adolescents. Pediatrics, 121, 37-45. doi:10.1542/peds.2007-3594

[28] Sanad, M. and Gharib, A. (2011) Evaluation of microalbuminuria in obese children and its relation to metabolic syndrome. Pediatric Nephrology, 26, 2193-2319. doi:10.1007/s00467-011-1931-9

[29] Salgado, C.M., Jardim, P.C., Teles, F.B. and Nures, M.C. (2009) Influence of low birth weight on microalbuminuria and blood pressure of school children. Clinical Nephrology, 71, 367-374.

[30] Becton, L.J., Kalpatthi, R.V., Rackoff, E., Disco, D., Orak, J.K., Jackson S.M. and Shatat, I.F. (2010) Prevalence and clinical correlates of microalbuminuria in children with sickle cell disease. Pediatric Nephrology, 25, 1505-1511. doi:10.1007/s00467-010-1536-8

[31] Rudberg, S., Aperia, A., Freyschuss, U. and Persson, B. (1990) Enalapril reduces microalbuminuria in young normotensive type 1 (insulin-dependent) diabetic patients irespective of its hypotensive effect. Diabetologia, 33, 470-476. doi:10.1007/BF00405108

[32] Adolescent Type 1 Diabetes Cardio-renal Intervention Trial Research Group (2009) Adolescent type 1 diabetes cardio-renal intervention trial (AdDIT). BMC Pediatrics, 9, 79.

[33] Jones, C.A., Francis, M.E., Eberhardt, M.S., Chavers, B., Coresh, J., Engelgau, M., Kusek, J.W., Byrd-Holt, D., Narayan, K.M., Herman, W.H., Jones, C.P., Salive, M. and Agodoa, L.Y. (2002) Microalbuminuria in the US popualtion: Third national health and nutrition examination survey. American Journal of Kidney Diseases, 39, 445459. doi:10.1053/ajkd.2002.31388

[34] Brandt, J.R., Jacobs, A., Raissy, H.H., Kelly, F.M., Staples, A.O., Kaufman, E. and Wong, C.S. (2010) Orthostatic proteinuria and the spectrum of diurnal variability of urinary protein excretion in healthy children. Pediatric Nephrology, 25, 1131-1137. doi:10.1007/s00467-010-1451-z

[35] Tsioufis, C., Mazaraki, A., Dimitriadis, K., Stefanidis, C.J. and Stefanadis, C. (2011) Microalbuminuria in the paediatric age: Current knowledge and emerging questions. Acta Paediatrica, 100, 1180-1184. doi:10.1111/j.1651-2227.2011.02291.x

[36] Kwak, B.O., Lee, S.T., Chung, S. and Kim, K.S. (2011) Microalbuminuria in normal Korean children. Yonsei Medical Journal, 52, 476-481. doi:10.3349/ymj.2011.52.3.476

[37] Kim, N.H., Pavkov, M.E., Knowler, W.C., Hanson, R.L., Weil, E.J., Curtis, J.M., Bennett, P.H. and Nelson, R.G. (2010) Predictive value of albuminuria in American Indian youth with or without type 2 diabetes. Pediatrics, 125, e844-e851. doi:10.1542/peds.2009-1230

[38] Rademacher, E., Mauer, M., Jacobs Jr., D.R., Chavers, B., Steinke, J. and Sinaiko, A. (2008) Albumin excretion rate in normal adolescents: Relation to insulin resistance and cardiovascular risk factors and comparisons to type 1 diabetes mellitus patients. Clinical Journal of the American Society of Nephrology, 3, 998-1005. doi:10.2215/CJN.04631007

[39] Rademacher, E.R. and Sinaiko, A.R. (2009) Albuminuria in children. Current Opinion in Nephrology and Hypertension, 18, 246-251. doi:10.1097/MNH.0b013e3283294b98

[40] Klausen, K., Borch-Johnsen, K., Feldt-Rasmussen, B., Jensen, G., Clausen, P., Scharling, H., Appleyard, M. and Jensen, J.S. (2004) Very low levels of microalbuminuria are associated with increased risk of coronary heart disease and death independently of renal function, hypertension, and diabetes. Circulation, 110, 32-35. doi:10.1161/01.CIR.0000133312.96477.48

[41] Chronic Kidney Disease Prognosis Consortium, Matsushita, K., Velde, M., Astor, B.C., Woodward, M., Levey, A.S., Jong, P.E., Coresh, J. and Gansevoort, R.T. (2010) Association of estimated glomerular filtration rate and albuminuria with all-cause and cardiovascular mortality in general population cohorts: A collaborative meta-analysis. Lancet, 375, 2073-2081. doi:10.1016/S0140-6736(10)60674-5

[42] Salgado, P.P., Silva, I.N, Vieira, E.C. and Simões e Silva, A.C. (2010) Risk factors for early onset of diabetic nephropathy in pediatric type 1 diabetes. Journal of Pediatric Endocrinology \& Metabolism, 23, 1311-1320.

[43] Roy, M.S., Affouf, M. and Roy, A. (2007) Six-year incidence of proteinuria in type 1 diabetic African Americans. Diabetes Care, 30, 1807-1812. doi:10.2337/dc06-2534

[44] Stone, M.L., Craig, M.E., Chan, A.K., Lee, J.W., Verge, C.F. and Donaghue, K.C. (2006) Natural history and risk factors for microalbuminuria in adolescents with type 1 diabetes: A longitudinal study. Diabetes Care, 29, 2072 2077. doi:10.2337/dc06-0239

[45] Galler, A., Haberland, H., Näke, A., Hofer, S., Holder, M., Raile, K. and Holl, R.W. and German Federal Ministry 
for Education and Research BMBF Competence Network of Diabetes Mellitus (2012) Natural course of untreated microalbuminuria in children and adolescents with type 1 diabetes and the importance of diabetes duration and immigrant status: Longitudinal analysis from the prospective nationwide German and Austrian diabetes survey DPV. European Journal of Endocrinology, 166, 493-501. doi:10.1530/EJE-11-0695

[46] Amin, R., Widmer, B., Prevost, A.T., Schwarze, P., Cooper, J., Edge, J., Marcovecchio, L., Neil, A., Dalton, R.N. and Dunger, D.B. (2008) Risk of microalbuminuria and progresson to macroalbuminuria in a cohort with childhood onset type 1 diabetes: Prospective observational study. BMJ, 336, 697-701.

doi:10.1136/bmj.39478.378241.BE

[47] Basiratnia, M., Abadi, F.S., Amirhakimi, G.H., Karamizadeh, Z. and Karamifar, H. (2012) Ambulatory blood pressure monitoring in children and adolescents with type-1 diabetes mellitus and its relation to diabetic control and microalbuminuria. Saudi Journal of Kidney Diseases and Transplantation, 23, 311-315.

[48] Dost, A., Klinkert, C., Kapellen, T., Lemmer, A., Naeke, A., Grabert, M., Kreuder, J. and Holl, R.W., DPV Science Initiative (2008) Arterial hypertension determined by ambulatory blood pressure profiles. Contribution to microalbuminuria risk in a multicenter investigation in 2105 children and adolescents with type 1 diabetes. Diabetes Care, 31, 720-725. doi:10.2337/dc07-0824

[49] Marcovecchio, M.L., Tossavainen, P.H., Acerini, C.L., Barrett, T.G., Edge, J., Neil, A., Shield, J., Widmer, B., Dalton, R.N. and Dunger, D.B. (2010) Maternal but not paternal association of ambulatory blood pressure with albumin excretion in young offspring with type 1 diabetes. Diabetes Care, 33, 366-371. doi:10.2337/dc09-1152

[50] Salardi, S., Balsamo, C., Zucchini, S., Maltoni, G., Scipione, M., Rollo, A., Gualandi, S. and Cicognani, A. (2011) High rate of regression from micro-macroalbuminuria to normoalbuminuria in children and adolescents with type 1 diabetes treated or not with enalapril: The influence of HDL cholesterol. Diabetes Care, 34, 424-429. doi:10.2337/dc10-1177

[51] Gheissari, A., Javanmard, S.H., Shirzadi, R., Amini, M. and Khalili, N. (2012) The effects of blocking angiotensin receptors an early stages of diabetic nephropathy. International Journal of Preventive Medicine, 3, 477-482.

[52] Burgert, T.S., Dziura, J., Yeckel, C., Taksali, S.E., Weiss, R., Tamborlane, W. and Caprio, S. (2006) Microalminuria in pediatric obesity: Prevalence and relation to other cardiovascular risk factors. International Journal of Obesity, 30, 273-280. doi:10.1038/sj.ijo.0803136

[53] Ariceta, G. (2011) Clinical practice: Proteinuria. European Journal of Pediatrics, 170, 15-20. doi:10.1007/s00431-010-1334-0

[54] Cosentino, F., Hishikawa, K., Katusic, Z.S. and Luscher, T.F. (1997) High glucose increases nitric oxide synthase expression and superoxide anion generation in human aortic endothelial cells. Circulation, 96, 25-28. doi:10.1161/01.CIR.96.1.25

[55] Franks, P.W., Hanson, R.L., Knowler, W.C., Sievers, M.L., Bennet, P.H. and Looker, H.C. (2010) Childhood obesity, other cardiovascular risk factors, and premature death. The New England Journal of Medicine, 362, 485-493. doi:10.1056/NEJMoa0904130

[56] Assadi, F.K. (2005) Value of urinary excretion of microalbumin in predicting glomerular lesions in children with isolated microscopic hematuria. Pediatric Nephrology, 20, 1131-1135. doi:10.1007/s00467-005-1928-3

[57] Imuetinyan, B.A., Okoeguale, M.I. and Egberue, G.O. (2011) Microalbuminuria in children with sickle cell anemia. Saudi Journal of Kidney Diseases and Transplantation, 22, 733-738.

[58] Puddu, M., Podda, M.F., Mussap, M., Tumbarello, R. and Fanos, V. (2009) Early detection of microalbuminuria and hypertension in children of very low birthweight. Journal of Maternal-Fetal and Neonatal Medicine, 22, 83-88. doi:10.1080/14767050802360809

[59] Schreuder, M.F., Langemeijer M.E., Bökenkamp, A., Delemarre-Van de Waal, H.A. and Van Wijk, J.A. (2008) Hypertension and microalbuminuria in children with congenital solitary kidneys. Journal of Paediatrics and Child Health, 44, 363-368. doi:10.1111/j.1440-1754.2008.01315.x

[60] Jensen, J.S., Feldt-Rasmussen, B., Strandgaard, S., Schroll, M. and Borch-Johnsen, K. (2000) Atrerial hypertension, microalbuminuria, and risk of ischemic heart disease. Hypertension, 35, 898-903. doi:10.1161/01.HYP.35.4.898

[61] Muiesan, M.L., Ambrosioni, E., Costa, F.V., Leonetti, G., Pessina, A.C., Salvetti, M., Trimarco, B., Volpe, M., Pontremoli, R., Deferrari, G. and Rosei, E.A. (2012) Sex differences in hypertension-related renal and cardiovascular diseases in Italy: The I-DEMAND study. Journal of Hypertension, 30, 2378-2386. doi:10.1097/HJH.0b013e328359b6a9

[62] Karpettas, N., Nasothimiou, E., Kollias, A., Vazeou, A., and Stergiou, G.S. (2013) Ambulatory and home blood pressure monitoring in children and adolescents: Diagnosis of hypertension and assessment of target-organ damage. Hypertension Research, 36, 285-292. doi:10.1038/hr.2012.220

[63] Hillenge, H.L., Janssen, W.M., Bak, A.A., Diercks, G.F., Grobbee, D.E., Crijns, H.J., Van Gilst, W.H., De Zeeuw D., De Jong, P.E. and Prevend Study Group (2001) Microalbuminuria is common, also in nondiabetic, nonhypertensive population, and an independent indicator of cardiovascular risk factors and cardiovascular morbidity. Journal of Internal Medicine, 249, 519-526. doi:10.1046/j.1365-2796.2001.00833.x

[64] Wachtell, K., Palmieri, V., Olsen, M.H., Bella, J.N., Aalto, T., Dahlof, B., Gerdts, E., Wright Jr., J.T., Papademetriou, V., Mogensen, C.E., Borch-Johnsen, K., Ibsen, H. and Devereux, R.B. (2002) Urine albumin/creatinine ratio and echocardiographic left ventricular structure and function in hypertensive patients with electrocardiographic left ventricular hypertrophy: The LIFE study. Losartan Intervention for Endpoint Reduction. American Heart Journal, 43, 319-326. doi:10.1067/mhj.2002.119895

[65] Okpere, A.N., Anochie, I.C. and Eke, F.U. (2012) Prevalence of microalbuminuria among secondary school children. African Health Sciences, 12, 140-147. 


\section{doi:10.4314/ahs.v12i2.10}

[66] Assadi, F. (2007) Effect of microalbuminuria lowering on regression of left ventricular hypertrophy in children and adolescents with essential hypertension. Pediatric Cardiology, 28, 27-33. doi:10.1007/s00246-006-1390-4

[67] National High Blood Pressure Education Program Working Group on High Blood Pressure in Children and Adolescents (2004) The fourth report on the diagnosis, evaluation, and treatment of high blood pressure in children and adolescents. Pediatrics, 144, 555-576.

[68] Lurbe, E., Cifkova, R., Cruickshank, J.K., Dillon, M.J.,
Ferreira, I., Invitti, C., Kuznetsova, T., Laurent, S., Mancia, G., Morales-Olivas, F., Rascher, W., Redon, J., Schaefer, F., Seeman, T., Stergiou, G., Wühl, E., Zan- chetti, A. and European Society of Hypertension (2009) Management of high blood pressure in children and adolescents: Recommendations of the European society of hypertension. Journal of Hypertension, 27, 1719-1742. doi:10.1097/HJH.0b013e32832f4f6b

[69] Varda, N.M. and Gregorič, A. (2005) A diagnostic approach for the child with hypertension. Pediatric $\mathrm{Ne}$ phrology, 20, 499-506. doi:10.1007/s00467-004-1737-0 